\title{
Carotid artery disease and stroke in patients with peripheral arterial disease. The role of inflammation
}

\author{
Patologia carotidea e Ictus in pazienti con arteriopatia \\ ostruttiva periferica. II ruolo della infiammazione
}

\author{
Giusy Sirico, Lucrezia Spadera, Mario De Laurentis, Gregorio Brevetti
}

\begin{abstract}
Carotid artery disease and stroke in patients with peripheral arterial disease. The role of inflammation. G. Sirico, L. Spadera, M. De Laurentis, G. Brevetti.

Although during the last decade there have been great advances in our knowledge of the epidemiology and pathophysiology of multi-district atherosclerotic disease, little is known about the association between peripheral arterial disease and carotid artery disease. This review was conceived to cast some light on this topic, paying special attention to inflammation which plays a pivotal role in atherosclerosis. An aspect of pathophysiologic and clinical relevance is that the coexistence of carotid disease is more frequent in peripheral arterial disease than in coronary artery disease, not only in terms of carotid stenosis, but also with respect to the presence of hypoechoic unstable plaque. These
\end{abstract}

\begin{abstract}
latter plaques present a large infiltration of macrophages and are associated to high levels of inflammatory markers. In particular, the greater prevalence of hypoechoic carotid plaques in peripheral arterial disease compared to patients with carotid artery disease was poorly related to classic risk factors, but showed an independent association with an increased number of leukocyte and neutrophil cells, which are reliable markers of inflammation. The greater prevalence of hypoechoic unstable carotid plaques could explain why peripheral arterial disease portends higher risk of stroke than coronary artery disease.
\end{abstract}

Keywords: peripheral arterial disease, carotid artery disease, stroke, polyvascular disease, inflammation.

Monaldi Arch Chest Dis 2009; 72: 10-17.

Department of Clinical Medicine and Cardiovascular and Immunological Sciences, University of Naples "Federico II".

Corresponding author: Gregorio Brevetti; MD, Via G. Iannelli 45/A, I-80131 Napoli, Italy; E-mail address: brevetti@unina.it; Telephone/Fax: +390817462240.

The arterial system is not a lifeless pipe network, but it should be seen as a whole anatomic and dynamic compartment often prone to a killer: the atherosclerosis. Indeed, atherosclerosis is a systemic disorder which frequently affects multiple vascular districts simultaneously $[1,2]$. In particular, peripheral arterial disease (PAD) is recognized as a marker of systemic atherosclerosis [3-6]. The REduction of Atherothrombosis for Continued Health (REACH) registry showed that, among patients with polyvascular disease, PAD was present in one half, cerebrovascular disease (CVD) in one third and coronary artery disease (CAD) in a quarter of the cases [7]. The most frequent association is that between PAD and CAD [7] and, indeed, more than $50 \%$ of PAD patients have a coexistent CAD [8-11] which sometimes is present in asymptomatic, although severe, form [12, 13]. Furthermore, PAD severity, measured as Ankle Brachial Index $(\mathrm{ABI})$, is related to the severity and extent of coronary atherosclerosis, assessed by angiography [14]. Therefore, not surprisingly, a low ABI carries an increased risk of suffering from both fatal and non fatal myocardial infarction $[15,16]$.

On the contrary, less is known about the implications of the presence of carotid disease in PAD [1723]. This is particularly unfortunate, because PAD af- fects about 27 million of persons in western countries and carotid disease is the principal cause of ischemic cerebrovascular events, which have an important socioeconomic impact, representing a main cause of disability and a relevant financial burden in terms of direct and indirect costs. Our aim was to provide a review of the available epidemiologic and pathophysiologic findings concerning the relationship of PAD with carotid artery disease and its related events.

\section{Carotid plaques in PAD patients}

The use of carotid duplex ultrasound is a non invasive technique able to provide reliable data on the burden of carotid artery atherosclerosis in PAD. Carotid intimal medial thickness (IMT) is increased in PAD, being $0.87 \mathrm{~mm}$ in patients with $\mathrm{ABI} \leq 0.9 \mathrm{vs}$ $0.80 \mathrm{~mm}$ in those with ABI $>0.9(P<0.01)$. Even more important, carotid IMT was related to the severity of leg atherosclerosis, being $0.90 \mathrm{~mm}$ in patients with intermittent claudication (IC) and $0.81 \mathrm{~mm}$ in asymptomatic patients in whom the presence of the PAD was evidenced by an ABI $\leq 0.90$ [17]. Consistent with the latter finding are the results of the Cardiovascular Health Study (CHS) [18] which showed that the relative risk for moderate $(50 \%-74 \%)$ and se- 
vere (75\%-100\%) carotid stenoses increased in a graded stepwise fashion as the ABI decreased. Mostaza Jose M. et al. [19] reported that it was $14.3 \%$ in PAD patients and only $4.7 \%$ in the control subjects, matched for age, sex, and major risk factors. Similarly, in our experience, the presence of $>50 \%$ carotid stenosis in PAD was $18.6 \%$ [20]. A lower prevalence was found in the Lower Extremity Arterial Disease (LEAD) substudy of the Bypass Angioplasty Revascularization Investigation (BARI) trial which reported carotid stenosis in $7 \%$ of PAD patients (BARI). In any case, such prevalence was markedly higher than in no PAD $(0.3 \%, P<0.001)[21]$.

An aspect of pathophysiologic and clinical relevance is that the coexistence of carotid disease is more frequent in PAD than in CAD. In particular, the Second Manifestation of ARTerial (SMART) disease study [22] showed that the prevalence of carotid stenosis $\geq 70 \%$ was $12.5 \%$ in PAD and only $3.1 \%$ in CAD. Similarly, in another series, carotid stenosis $\geq 70 \%$ was present in $24.5 \%$ of PAD patients and $11.1 \%$ of CAD patients [23].

These data may partly explain the higher incidence of stroke in PAD vs CAD [7, 24]. However, many cerebrovascular events are associated with carotid stenoses $<75 \%$, thus indicating that other mechanisms are involved such as cardiac or aortic embolism, lacunar infarction, valvular disease with atrial fibrillation, and embolism from carotid bifurcation. The latter event appears to be the most common pathogenetic mechanism for cerebral ischemia [25, 26]. Actually, histopathologic data have led to the concept that plaques with a soft lipid-rich core, a thin cap, and inflammation in cap and shoulder are unstable and prone to rupture [27-35].
This type of plaques may be identified at B-mode ultrasound scanning. Plaques that appear with low echogenicity have an increased lipid content, while plaques with high echogenicity consist mainly of fibrin and collagen, which make them more stable $[36,37]$. More in detail, plaques may be divided as echolucent (type 1), predominantly echolucent (type 2), predominantly echogenic (type 3 ), echogenic (type 4), or calcified (type 5) [38] (Fig. 1).

To the best of our knowledge, only two studies compared the prevalence of carotid plaque echogenicity in patients affected by PAD [20, 39] to that observed in CAD subjects. In the first paper, PAD patients with carotid atherosclerosis but without CAD, showed a prevalence of hypoechoic plaques (type $1+$ type 2) of $39.5 \%$ [20]. A similar result was obtained when carotid plaque echogenicity was assessed by grey-scale median (GSM) analysis $(34.9 \%)$. Both these proportions were markedly higher than those observed in CAD patients without PAD [20]. Actually, in the latters, the percentage of patients with hypoechoic carotid plaques was only $18.6 \%$ at visual $(\mathrm{p}=0.033)$ and $14.0 \%$ at GSM analysis $(p=0.024)$ [20]. Compared to CAD patients, those with PAD showed an increased risk of having hypoechoic plaque both at visual (OR 4.39, 95\% CI 1.21-15.92) and GSM (OR 5.13, 95\% CI 1.2720.67) analysis, after adjustment for age, male, sex, hypertension and body mass index [15]. Given these results, it is not surprising that, in the second paper, hypoechoic carotid plaques (i.e. those with a GSM < $25^{\text {th }}$ percentile) resulted more prevalent in CAD+PAD patients than in those with isolated CAD (38.0\% vs $11.4 \%, \mathrm{p}<0.001)$ [39].

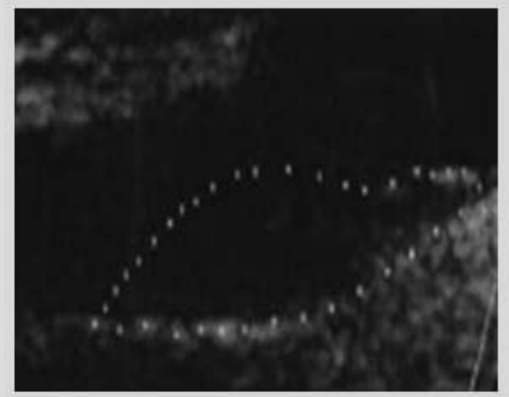

Type 1: echolucent

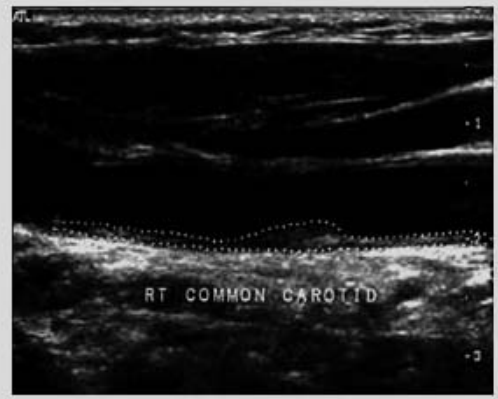

Type 2: predominantly echolucent

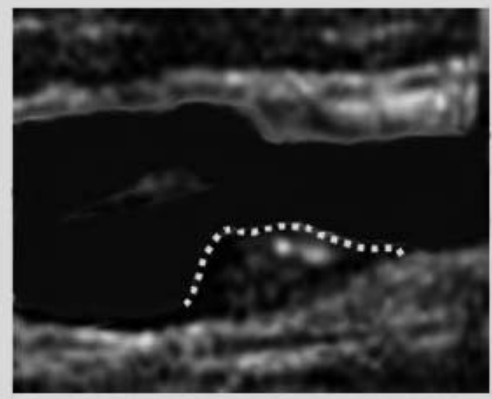

Type 3: predominantly echogenic

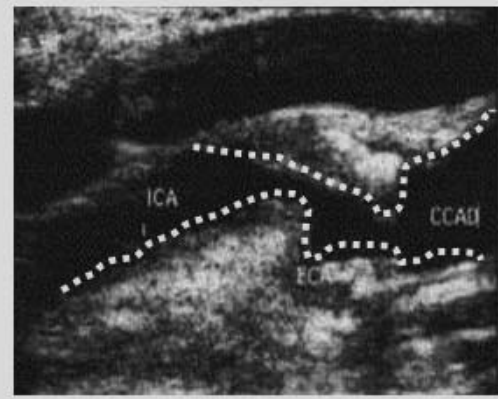

Type 4: echogenic

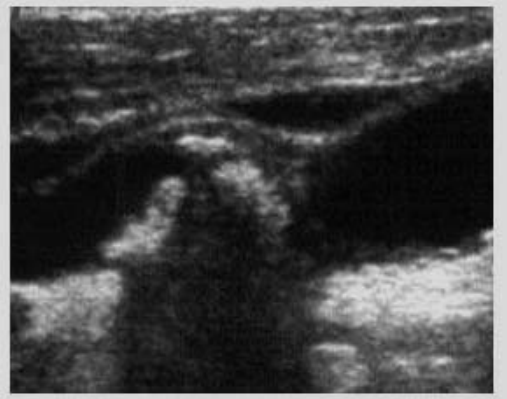

Type 5: calcified

Figure 1. - Carotid plaque classified according to their echogenicity. 
In both the aforementioned studies [20, 39] the greater prevalence of hypoechoic carotid plaques in PAD vs CAD patients was poorly related to classic risk factors but showed an independent association with an increased number of leukocyte and neutrophil cells, which are reliable markers of inflammation. This is consistent with previous results showing that in PAD subjects the inflammatory profile is more pronounced than in CAD patients [20].

\section{Inflammation and carotid disease}

Atherosclerosis can be considered as an expression of chronic inflammation which, in addition to favor the development of plaques, plays a prominent role in their instability [40-43]. Several clinical and histopathological studies indicate that the severity of the carotid artery disease is related to inflammation. In 5201 participants in the Cardiovascular Health Study (CHS) [44], a weak but significant correlation was found between C-Reactive Protein (CRP) levels and carotid IMT ( $\mathrm{r}=0.12, P=0.001)$. Mullinex et al. [45] compared 72 patients with carotid stenosis with 74 healthy subjects without carotid stenosis, and found that in the formers CRP levels roughly doubled those observed in patients without carotid stenosis $(3.7 \pm 6.1$ vs $1.9 \pm 2.1 \mathrm{mg} / \mathrm{L}, \mathrm{p}=0.02)$. Even more important, increased levels of CRP paralleled an increase in the degree of carotid artery stenosis. Actually, each additional $1 \mathrm{mg} / \mathrm{dL}$ of baseline serum CRP level corresponded with a $5.2-\mathrm{cm} / \mathrm{s}$ increase in carotid duplex velocity magnitude $(P<0.01)$ [45]. Similarly, in the Inflammation and Carotid ArteryRisk for Atherosclerosis Study (ICARAS) [46], lev- els of CRP and serum amyloid A (SAA) at baseline and follow-up, and the change from baseline to follow-up were significantly associated with progression of carotid atherosclerosis assessed by Peak Systolic Velocity of internal carotid artery and NASCET criteria [47]. Actually, adjusted Odds Ratios (ORs) for atherosclerosis progression for increased quintiles of baseline CRP were 1.65 (0.71 to 3.84$), 1.87$ (0.8 to 4.37 ), 3.32 (1.49 to 7.39 ), and 3.65 (1.65 to 8.08), respectively, compared with the lowest quintiles [46]. The corresponding ORs for baseline SAA were 0.86 (0.38 to 1.92$), 0.99$ (0.49 to 1.99$), 1.72$ (0.91 to 3.28), and 2.28 (1.24 to 4.20) [46].

However, inflammation is related not only to the degree of plaque stenosis but also to the plaque morphology, which plays a distinct pathophysiological role in the development of stroke [44, 48, 49]. Indeed, for a given critical stenosis plaque surface and composition may be responsible for plaque disruption and distal embolization [25, 26] (Fig. 2).

The CHS reported that, when patients were classified as having high-risk carotid plaques (irregular or ulcerated surface of hypoechoic plaques), intermediate-risk plaques (hyperdense, calcified plaques or those with mildly irregular surface) and no plaques, CRP levels increased from the group without plaques, group with intermediate-risk plaques, to plaques at high-risk [44]. Consistently, Alvarez Garcia et al. [49] measured CRP levels 48 hours before carotid surgery, and found that patients with histologically defined unstable plaques had a higher median CRP value $(27.1 \mathrm{mg} / \mathrm{L})$ than those with stable plaques $(4.1$ $\mathrm{mg} / \mathrm{L})(\mathrm{p}<0.001)$. Similarly, Lombardo et al. [50] reported that in CAD, CRP levels were higher in pa-

\section{CHARACTERISTICS OF INFLAMED UNSTABLE PLAQUE}

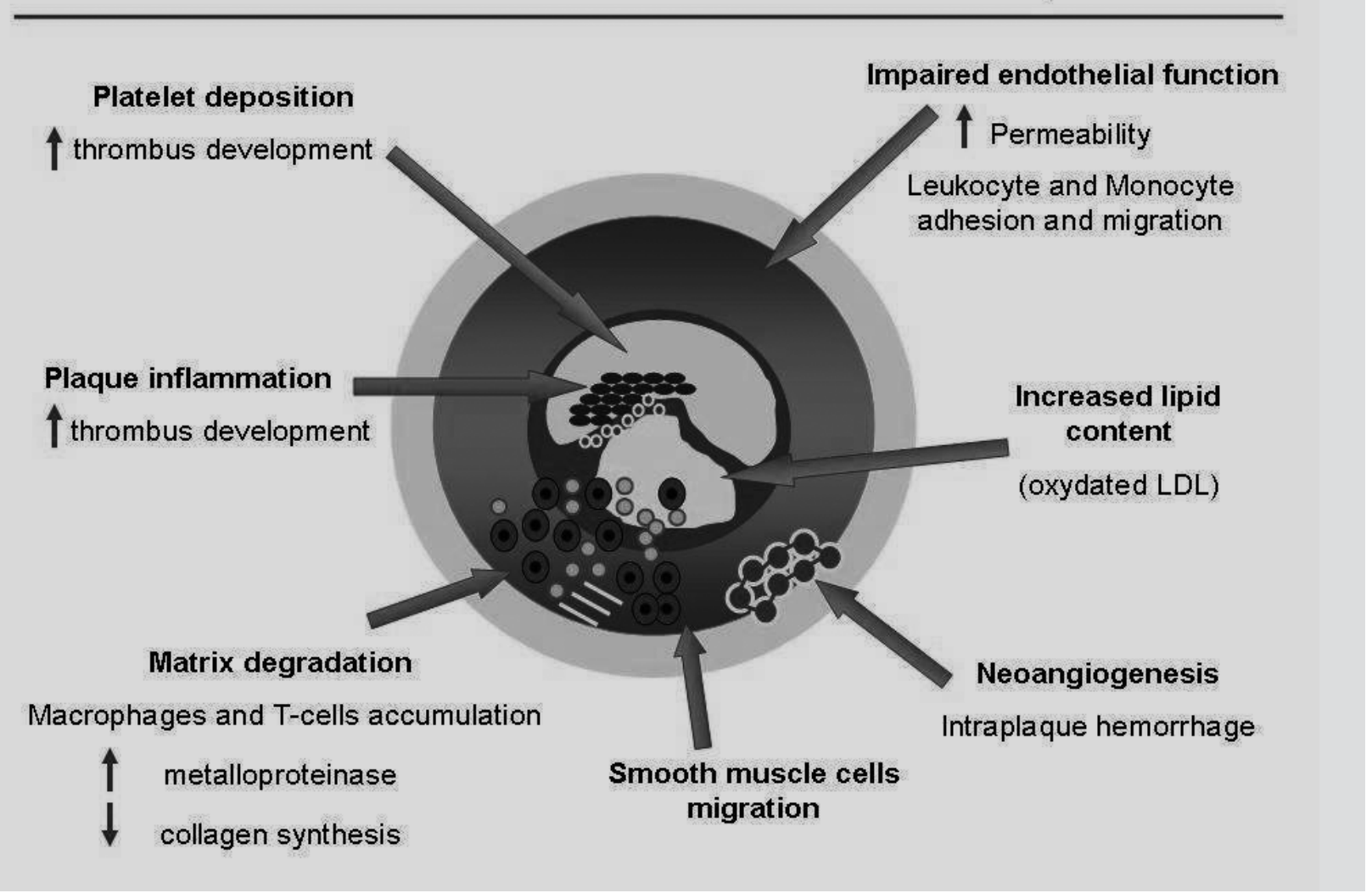

Figure 2. - Characteristics of inflamed unstable plaque. 
tients with echoically complex unstable carotid plaques than in those with stable plaques. A more direct evidence of the relationship between unstable carotid plaques and inflammation emerges from histopathological studies. Jander et al. [51] performed a quantitative immunocytochemical analysis of inflammatory infiltration in endarterectomy specimens from 37 patients undergoing carotid surgery and asked whether the extent of inflammation correlated to plaque instability as evidenced clinically by both the presence of ischemic symptoms and the rate of cerebral microembolism assessed by transcranial Doppler ultrasonography. Statistical analyses revealed that the percentage of macrophage-rich areas and the number of T-cells per $\mathrm{mm}^{2}$ section area were significantly higher in recently symptomatic than in asymptomatic patient. Furthermore, macrophage infiltration was more pronounced in micro-embolismpositive than in micro-embolism negative patients. Consistently, in a series of 106 patients undergoing carotid endoarterectomy, macrophages were found to be particularly common in plaques with a high content of lipid and hemorrhage and, conversely, rare in plaques dominated by calcification and fibrous tissue [52]. In addition, macrophage density in carotid artery plaques classified by B-mode ultrasound images as echolucent, intermediate, or echorich was $1.8 \% \pm 0.2 \%, 1.5 \% \pm 0.4 \%$ and $1.0 \% \pm 0.2 \%(P=0.02$ at analysis of variance). A recent immunochemistry study reports that CD36, a scavenger receptor involved in lipid uptake and inflammation, is localized to macrophages-rich area of intima within the carotid atherosclerotic lesions. Furthermore, plasma levels of soluble CD36 were markedly higher in patients with recent cerebrovascular symptoms ( $\leq 2$ months) [53].

Finally, and extremely important from a therapeutic point of view, macrophage density in carotid artery was significantly lower in patients using aspirin than in non users $(1.2 \% \pm 0.2 \%$ vs $1.8 \% \pm 0.2 \%$, $P=0.01$ ) [51]. Relevant in this regard are the data of a recent paper which, in addition to confirm the inflammatory infiltration in unstable carotid plaques, demonstrated that patients treated with statins had lower percentage values of macrophage area and metalloproteinase- 9 area than untreated patients. This provides further evidence to support the hypothesis that statins reduce the inflammatory response and thereby stabilize carotid atherosclerotic plaques [54].

\section{PAD, inflammation and Carotid disease}

Despite the large evidence of the strict relationship between inflammation and carotid artery disease, this aspect has been poorly investigated in PAD, although affected individuals have a more severe inflammatory status than controls [55-57] and a higher prevalence of carotid disease [22, 23].

In our laboratory, we found a significant inverse relationship between the echogenicity of carotid plaques measured by GSM analysis and the number of neutrophils $(\rho=-0.423, P<0.01)$. Thus, the greater the plaque instability, the higher inflammatory status. Indeed, the number of neutrophils was higher in type 1 and 2 plaques (considered collectively) than in the subgroup comprising type 3 and 4 plaques $(4.9 \pm 1.0$ vs $3.8 \pm 1.1109 / 1, P<0.01$ ) [20], and the hypoechoic plaques were much more common in the group of patients with neutrophil number exceeding the median than in those with lower neutrophil levels $(48.8 \%$ vs $9.3 \%, P<0.01$, for visual analysis, and $41.9 \%$ vs $7.0 \%, P<0.01$, for GSM analysis). Notably, the increased risk associated with PAD of having hypoechoic plaques was no longer significant when the neutrophil number exceeding the median was added to the multivariate analyses. In this model, only an increased neutrophil count was independently associated with the presence of hypoechoic plaques. Indeed, PAD patients showed a greater number of neutrophils than those with CAD $(4.4 \pm 1.0$ vs $3.9 \pm 1.2$ $\left.10^{9} / 1, \mathrm{p}=0.03\right)$. Therefore, the finding that the prevalence of hypoechoic carotid plaques was higher in PAD than in CAD patients was probably because, consistent with previous studies [58, 59], the PAD group had a more pronounced inflammatory profile than CAD patients. Similar findings were observed in a subsequent study [39] comparing CAD patients with a coexistent PAD vs those with CAD alone. Indeed, the leukocyte number was greater in CAD+PAD than in CAD alone, and when the leukocyte number higher than the median was included in multivariate analysis, it showed an association with hypoechoic plaques (OR 6.70, 95\% CI 2.13 to 21.10, $\mathrm{p}=0.001)$ stronger than that observed for the presence of PAD (OR 4.20, 95\% CI 1.45 to $12.14, \mathrm{p}=0.008$ ) [39]. These data are consistent with those of a previous study showing that in patients with acute myocardial infarction, the leukocyte number increase proportionally to the number of carotid plaques defined unstable on B-mode ultrasound [60].

Therefore, in patients with CAD, the coexistence of PAD entails not only a more severe CAD [58, 59, 14], but even a more severe carotid disease [39]. Conceivably, this is due to a more aggressive atherosclerosis, which however is only in part due to classic risk factors [58, 14]. Rather, it appears to be independently associated with inflammation. $(\mathbf{6 1 , 6 2})$ What remains to be determined is whether and to what extent the high levels of inflammatory markers result from a primary "extravascular" activation of the acute phase response, or whether they originate from the site of the active plaques. The two mechanisms are not mutually exclusive. However, because inflamed plaques are common in femoral arteries [63, 64], and the peripheral vascular bed provides a large surface for the release of inflammatory molecules, it is intriguing to speculate that an inflammatory response generated in the affected limb of PAD patients could impair arterial vessels at distant sites. In actual fact, CAD + PAD who had, in the affected limb, a transfemoral gradient of interleukin-6 (IL-6) and myeloperoxidase (MPOX) greater than the median showed a more severe CAD than those with a lower local inflammatory status [58, 65]. Furthermore, serum from the claudicant limb of CAD+PAD patients induced a proinflammatory state in human coronary artery endothelial cells (HCAECs) in vitro. HCAECs released more MCP-1 when exposed to serum from the affected limb than when exposed to serum from the aorta of the same patients. This difference disappeared when HCAECs were incubated with serum from healthy legs or the aorta of CAD-alone patients [58]. Therefore, it is reasonable to assume that, consequent to the presence of inflamed 
plaques, the blood leaving the affected limb of PAD patients contains substances that affect the endothelial cells of the other vascular districts. Accordingly, we investigated whether hypoechoic, presumably inflamed, femoral plaques, entail a high risk of hypoechoic carotid plaques. Femoral and carotid plaques of 102 consecutive patients with peripheral artery disease (PAD) were studied echoically and classified as echolucent or echorich according to the GSM value, which was 53.6 for femoral and 55.2 for carotid plaques. Serum CRP and neutrophil count were also measured. Echolucent carotid plaques were more frequent in patients with echolucent than in those with echorich femoral plaques $(55.8 \%$ vs $32.0 \%$, p $<0.01)$. Compared to patients with echorich femoral plaques, those with echolucent femoral plaques showed higher levels of both high-sensitivity CRP (2.0 [1.4-3.5] $\mathrm{mg} / \mathrm{L}$ vs 3.6 [2.5-5.8] mg/L $(\mathrm{p}<0.01))$ and neutrophil count (4.1 [2.9-4.9] x 103/ $\mu \mathrm{L}$ vs 4.5 [3.9-5.4] x $103 / \mu \mathrm{L}$ $(p=0.029))[66]$. At multivariate analysis, adjusted for age, sex, diabetes, active smoking, hypercholesterolemia, and hypertension, when hs-CRP and neutrophil count were added to the other covariates, only the latter was associated with echolucent carotid plaques (OR 5.71, 95\% CI 1.37-23.85, p=0.017). Noteworthy, in this model the association between femoral and carotid echolucency was attenuated (OR $3.75,95 \%$ CI $0.98-14.43, \mathrm{p}=0.05$ ) [66]. Thus, the higher prevalence of echolucent carotid plaques in patients with echolucent femoral plaques is likely consequent to the marked inflammatory profile of the latters. Therefore, it remains to be established whether the coexistence of echolucent plaques in the femoral and carotid arteries individuates a vulnerable patient or is consequent of the release of inflammatory molecules from the arterial bed of the affected limb.

On the other hand, high-risk plaque has been suggested to be a multivessel phenomenon [50, 65, $67,68]$. However, whichever of the two mechanisms is operating, there is need of future prospective studies to assess whether echolucent femoral plaque portents a higher risk of ischemic cerebral events, as compared to echorich femoral plaque [66].

\section{PAD and stroke}

Stroke s the second most common cause of death after ischemic heart disease, represents a major cause of disability, and accounts for more than $4 \%$ of direct health costs in industrialized countries [69]. PAD carries an increased stroke risk, which al least in the Northern Manhattan Study [70], appears to be less striking than myocardial infarction. Actually, patients with self-reported PAD showed a higher incidence of myocardial infarction vs those without PAD ( $p=0.003$ at Log Rank Test), while no group difference was observed for ischemic stroke $(\mathrm{p}=0.604)$. In the Atherosclerosis Risk in Community (ARIC) Study [71], the strong association between PAD and stroke at univariate analysis was no longer significant after adjustment for major risk factors. Similarly, the CHS [18] reported that PAD was associated with $60 \%$ increased risk of stroke in those without previously diagnosed cardiovascular disease, but this association disappeared after adjustment for confounding factors. Also the Edimburgh Artery Study [15], after adjust- ment for age, did not show any association between PAD and risk of stroke. Different from what reported above, other studies testify that PAD and its severity show an incidence of ischemic stroke even greater than that observed in CAD. The Clopidogrel versus Aspirin in Patients at Risk of Ischemic Events (CAPRIE) study [24] showed that the occurrence of fatal and non fatal stroke at follow up in the PAD subgroup was double that in the myocardial infarction subgroup, in both the clopidogrel and aspirin arm. Furthermore, the Reduction of Atherothrombosis for Continued Health (REACH) Registry reported a greater 1-year stroke incidence in PAD patients with concomitant cerebrovascular disease than in patients with CAD and cerebrovascular disease [7].

With respect to the relationship between $\mathrm{ABI}$ and stroke risk, retrospective data from the National Health and Nutrition and Examination Survey [72] showed that more subjects with $\mathrm{ABI} \leq 0.9$ versus those with $\mathrm{ABI}>0.9$ had experienced a stroke (12.7\% vs $5.4 \%, \mathrm{p}<0.001)$. With the full ABI range, stroke presence rose with decreasing $\mathrm{ABI}$, although, after adjustment for potential confounders, only ABI $\leq 0.9$ and 0.9-0.99 remained significantly associated with the presence of stroke as compared with the reference group (ABI 1.10-1.29). Consistently, the Honolulu Heart program found a significant 2-fold increased risk of stroke in men with PAD among 2767 men aged 71 to 93 years during 3 to 6 years of follow-up [73]. The rate of fatal and non fatal stroke was $6 \%$ in men with PAD (ABI <0.9) compared with $2.9 \%$ in men without PAD [73]. After adjustment for other risk factors, the risk of total and thromboembolic stroke increased with declining ABI [73]. Therefore, studies on the relationship between PAD and stroke risk provide conflicting results. In any case, although PAD may not be predictor of stroke, it is a marker of disease and future events.

\section{PAD, inflammation and stroke}

Inflammation plays a role in the genesis of brain ischemia and inflammatory processes and may facilitate serious and life-threatening complication in stroke patients [74]. However, few is known about the association between inflammation and stroke in PAD patients. This because the large majority of studies investigating the relationship between inflammation and natural history of PAD included stroke in a composite of cardiovascular events.

Between 1996 and 2003, 384 patients with symptomatic PAD or symptomatic cerebrovascular disease or both were enrolled in National Institutes of Healthsponsored blinded prospective trial evaluating the effects of multiple atherosclerotic risk factors on progression of symptomatic PAD [75]. Baseline levels of CRP and D-dimer were obtained in 332 subjects. Results showed no relationship between the baseline levels of these inflammatory markers and stroke [75]. More recently, a prospective study including specifically patients with symptomatic PAD showed an increased incidence of stroke for each increasing quartile of CRP [76]. However no significant group difference was observed. On the contrary, inflammation has been found to predict the risk of first ischemic stroke in apparently healthy men [77], future is- 
chemic stroke and TIA in the elderly [78] and fatal stroke in the elderly [79]. The importance of inflammation in stroke is highlighted by the finding that levels of inflammatory molecules are increased within 24 hours after the onset of stroke [80-82]. Sequential blood studies demonstrate significantly elevated CRP and white blood cell (WBC) counts even 3 months after the onset of stroke [83]. Furthermore, histopathologic studies report that neutrophil recruitment starts from the first day after stroke, comes to its peak within 2-3 days and disappears after 1 week. Macrophage infiltration starts about 3 days after symptom onset and lasts for several years or decades, in the region infarction $[84,85]$.

\section{Conclusion}

Although during the last decade there have been great advances in our knowledge on the epidemiology and pathophysiology of carotid arteriopathy, little is known about the association between PAD and carotid artery disease. This review was conceived to cast some light on this topic, but many issues remain to be confirmed or clarified. In particular, more extensive studies are needed to ascertain whether the greater severity of carotid atherosclerosis in PAD vs CAD patients is only due to the more pronounced inflammatory profile of the formers.

Furthermore, it remains to be established whether, among PAD patients, a lower ABI portends a higher risk of stroke. Finally, it should be investigated the role of CRP and other inflammatory molecules as specific markers of stroke risk in PAD.

\section{Riassunto}

Benché il carattere polidistrettuale dell'aterosclerosi sia ben definito, pochi sono i dati a riguardo della specifica associazione tra arteriopatia periferica e malattia carotidea. Lo scopo di questo articolo è di riassumere i dati epidemiologici sulla coesistenza delle due malattie e di cercare di far luce su alcuni meccanismi fisiopatologici che favoriscono la loro associazione, con particolare attenzione per l'infiammazione che occupa un ruolo strategico nella malattia aterosclerotica. Un aspetto degno di attenzione è il fatto che la malattia carotidea si manifesti con più frequenza e con maggiore severità nei pazienti arteriopatici che in quelli affetti da cardiopatia ischemica. Infatti, all'esame ecocolordoppler, i pazienti con arteriopatia degli arti inferiori presentano una maggior prevalenza di placche ipoecoiche, che essendo caratterizzate da un elevato contenuto lipidico ed infiltrato di macrofagi, risultano instabili e quindi suscettibili alla formazione di trombi ed alla embolizzazione nel territorio vascolare cerebrale. Questo dato risulta associato in maniera indipendente ad elevati livelli sierici di leucociti e neutrofili, dimostrando negli arteriopatici un profilo infiammatorio più severo. Tale risultato potrebbe contribuire a spiegare il motivo per il quale i pazienti affetti da arteriopatia periferica presentino un più alto rischio di stroke rispetto a quelli portatori di malattia coronarica.

Parole chiave: arteriopatia obliterante degli arti inferiori, malattia carotidea, ictus cerebri, malattia polidistrettuale, infiammazione.

\section{ABBREVIATION LIST}

PAD: Peripheral Arterial Disease

CVD: Cerebrovascular Disease

CAD: Coronary Artery Disease

ABI: Ankle Brachial Index

IMT: Intimal Medial Thickness

IC: Intermittent Claudication

OR: Odds Ratio

CI: Confidence Interval

GSM: Grey-Scale Median

WBC: White Blood Cell

CRP: C-Reactive Protein

SAA: Serum Amyloid A

IL-6: Interleukin-6

MPOX: myeloperoxidase

HCAECs: human coronary artery endothelial cells

REACH: The REduction of Atherothrombosis for Continued Health

CHS: Cardiovascular Health Study

LEAD: Lower Extremity Arterial Disease

BARI: Bypass Angioplasty Revascularization Investigation

SMART: the Second Manifestation of ARTerial disease

ICARAS: Carotid Artery-Risk for Atherosclerosis Study

NASCET: North American Symptomatic Carotid Endarterectomy

Trial Collaborators

ARIC: Atherosclerosis Risk in Community

CAPRIE: The Clopidogrel versus Aspirin in Patients at Risk of Ischemic Events

\section{References}

1. Solberg LA, Strong JP. Risk factors for atherosclerotic lesions: a review of autopsy studies. Atherosclerosis 1983; 3: $187-187$.

2. Goldstein JA. Angiographic plaque complexity: the tip of the unstable plaque iceberg. J Am Coll Cardiol 2002; 39: 1464-7.

3. Brevetti G, Oliva G, Silvestro A, Scopacasa F, Chiariello M; Peripheral Arteriopathy and Cardiovascular Events (PACE) Study Group. Prevalence, risk factors and cardiovascular comorbidity of symptomatic peripheral arterial disease in Italy. Atherosclerosis 2004; 175(1): 131-8.

4. Fowkes FG, Housley E, Cawood EH, Macintyre CC, Ruckley CV, Prescott RJ. Edimburgh Artery Study: prevalence of asymptomatic and symptomatic peripheral arterial disease in the general population. Int J Epidemiol 1991; 20: 384-92.

5. Stoffers HE, Rinkens PE, Kester AD, Kaiser V, Knottnerus JA. The prevalence of asymptomatic and unrecognized peripheral arterial occlusive disease. Int J Epidemiol 1996; 25(2): 282-90.

6. Meijer WT, Hoes AW, Rutgers D, Bots ML, Hofman A, Grobbee DE. Peripheral arterial disease in the elderly: The Rotterdam Study. Arterioscler Thromb Vasc Biol 1998; 18(2): 185-92.

7. Steg PG, Bhatt DL, Wilson PW, et al; REACH Registry Investigators. One-year cardiovascular event rates in outpatients with atherothrombosis. JAMA 2007; 297(11): 1197-206.

8. Dormandy J, Mahir M, Ascady G, et al. Fate of the patient with chronic leg ischaemia. A review article. J Cardiovasc Surg 1989; 30(1): 50-7. Review.

9. Aronow WS, Ahn C. Prevalence of coexistence of coronary artery disease, peripheral arterial disease, and atherothrombotic brain infarction in men and women $>$ or = 62 years of age. Am J Cardiol 1994; 74(1): 64-5.

10. Hertzer NR, Beven EG, Young JR, et al. Coronary artery disease in peripheral vascular patients. A classification of 1000 coronary angiograms and results of surgical management. Ann Surg 1984; 199(2): 223-33.

11. Hirsch AT, Halverson SL, Treat-Jacobson D, et al. The Minnesota Regional Peripheral Arterial Disease Screening 
Program: toward a definition of community standards of care. Vasc Med 2001; 6(2): 87-96.

12. Darbar D, Gillespie N, Main G, et al. Prediction of late cardiac events by dipyridamole thallium scintigraphy in patients with intermittent claudication and occult coronary artery disease. Am J Cardiol 1996; 78(7): 736-40.

13. Perrone-Filardi P, Cuocolo A, Brevetti G, et al. Relation of brachial artery flow-mediated vasodilation to significant coronary artery disease in patients with peripheral arterial disease. Am J Cardiol 2005; 96(9): 1337-41.

14. Papamichael CM, Lekakis JP, Stamatelopoulos KS, et al. Ankle-brachial index as a predictor of the extent of coronary atherosclerosis and cardiovascular events in patients with coronary artery disease. Am J Cardiol 2000; 86(6): 615-8.

15. Leng GC, Lee AJ, Fowkes FG, et al. Incidence, natural history and cardiovascular events in symptomatic and asymptomatic peripheral arterial disease in the general population. Int J Epidemiol 1996; 25(6): 1172-81.

16. Criqui MH, Langer RD, Fronek A, et al. Mortality over a period of 10 years in patients with peripheral arterial disease. N Engl J Med 1992; 326(6): 381-6.

17. Allan PL, Mowbray PI, Lee AJ, Fowkes FG. Relationship between carotid intima-media thickness and symptomatic and asymptomatic peripheral arterial disease. The Edinburgh Artery Study. Stroke 1997; 28(2): 348-53.

18. Newman AB, Siscovick DS, Manolio TA, et al. Anklearm index as a marker of atherosclerosis in the Cardiovascular Health Study. Cardiovascular Heart Study (CHS) Collaborative Research Group. Circulation 1993; 88(3): 837-45.

19. Mostaza JM, González-Juanatey JR, Castillo J, Lahoz C, Fernández-Villaverde JM, Maestro-Saavedra FJ. Prevalence of carotid stenosis and silent myocardial ischemia in asymptomatic subjects with a low ankle-brachial index. $J$ Vasc Surg 2008. [Epub ahead of print].

20. Gregorio Brevetti, MD, Giusy Sirico, MD, Simona Lanero, MD, Julieta Isabel De Maio, MD, Eugenio Laurenzano, MD, Giuseppe Giugliano, MD. The prevalence of hypoechoic carotid plaques is greater in peripheral than in coronary artery disease and is related to the neutrophil count. J Vasc Surg 2008; 47: 523-9

21. Burek KA, Sutton-Tyrrell K, Brooks MM, et al. Prognostic importance of lower extremity arterial disease in patients undergoing coronary revascularization in the Bypass Angioplasty Revascularization Investigation (BARI). J Am Coll Cardiol 1999; 34(3): 716-21.

22. Kurvers HA, van der Graaf Y, Blankensteijn JD, Visseren FL, Eikelboom BC; SMART Study Group. Screening for asymptomatic internal carotid artery stenosis and aneurysm of the abdominal aorta: comparing the yield between patients with manifest atherosclerosis and patients with risk factors for atherosclerosis only. J Vasc Surg 2003; 37: 1226-33.

23. Cheng SW, Wu LL, Lau H, Ting AC, Wong J. Prevalence of significant carotid stenosis in Chinese patients with peripheral and coronary artery disease. Aust $N Z J$ Surg 1999; 69: 44-47.

24. A randomised, blinded, trial of clopidogrel versus aspirin in patients at risk of ischaemic events (CAPRIE). CAPRIE Steering Committee. Lancet 1996; 348(9038): 1329-39.

25. Langsfield M, Gray-Weale AC, Lusby RJ. The role of plaque morphology and diameter reduction in the development of new symptoms in asymptomatic carotid arteries. J Vasc Surg 1989; 9: 548-57.

26. Barnett HJ, Gunton RW, Eliasziw M, et al. Causes and severity of ischemic stroke in patients with internal carotid artery stenosis. JAMA 2000; 283: 1429-36.

27. Virmani R, Burke AP, Kolodgie FD, Farb A. Vulnerable plaque: the pathology of unstable coronary lesions. $J$ Interv Cardiol 2002; 15(6): 439-46.

28. Falk E, Shah PK, Fuster V. Coronary plaque disruption. Circulation 1995; 92(3): 657-71. Review
29. Davies MJ, Richardson PD, Woolf N, Katz DR, Mann J. Risk of thrombosis in human atherosclerotic plaques: role of extracellular lipid, macrophage, and smooth muscle cell content. Br Heart J 1993; 69(5): 377-81.

30. Fuster V, Lewis A. Connor memorial lecture: mechanisms leading to myocardial infarction: insights from studies of vascular biology. Circulation 1994; 90: 21262146.

31. Davies MJ, Thomas AC. Plaque fissuring: the cause of acute myocardial infarction, sudden ischaemic death, and crescendo angina. Br Heart J 1985; 53: 363-373.

32. Richardson PD, Davies MJ, Born GVR. Influence of plaque configuration and stress distribution on fissuring of coronary atherosclerotic plaques. Lancet 1989; 2: 941-94.

33. van der Wal AC, Becker AE, van der Loos CM, Das PK. Site of intimal rupture or erosion of thrombosed coronary atherosclerotic plaques is characterized by an inflammatory process irrespective of the dominant plaque morphology. Circulation 1994; 89: 36-44.

34. Moreno PR, Falk E, Palacios IF, Newell JB, Fuster V, Fallon JT. Macrophage infiltration in acute coronary syndromes: implications for plaque rupture. Circulation 1994; 90: 775-778.

35. Tauth J, Pinnow E, Sullebarger JT, et al. Predictors of coronary arterial remodeling patterns in patients with myocardial ischemia. Am J Cardiol 1997; 80(10): 1352-5.

36. Grǿnholdt MLM, Nordestgaard BG, Wiebe BM, Wilhjelm JE, Sillesen H. Echo-lucency of computerized ultrasound images of carotid atherosclerotic plaques are associated with increased levels of triglyceride-rich lipoproteins as well as increased plaque lipid content. Circulation 1998; 97: 34-40.

37. Lal BK, Hobson RW 2nd, Pappas PJ, et al. Pixel distribution analysis of B-mode ultrasound scan images predicts histologic features of atherosclerotic carotid plaques. $J$ Vasc Surg 2002; 35: 1210-7.

38. Geroulakos G, Ramaswami G, Nicolaides A, et al. Characterization of symptomatic and asymptomatic carotid plaques using high-resolution real-time ultrasonography. Br J Surg 1993; 80(10): 1274-7.

39. Brevetti G, Sirico G, Giugliano G, et al. Prevalence of hypoechoic carotid plaques in coronary artery disease: relationship with coexistent peripheral arterial disease and leukocyte number. Vascular Medicine 2008; 00: 1-7.

40. Lusis AJ. Atherosclerosis. Nature 2000; 407: 233-241.

41. Ross R. Atherosclerosis: an inflammatory disease. $N$ Engl J Med 1999; 340: 115-126.

42. Libby P, Ridker P, Maseri A. Inflammation and atherosclerosis. Circulation 2002; 105: 1135-1143.

43. Glass CK, Witztum JL. Atherosclerosis: the road ahead. Cell 2001; 104: 503-516.

44. Jie J. Cao, Alice M. Arnold, Teri A. Manolio, et al. Association of Carotid Artery Intima-Media Thickness, Plaques, and C-Reactive Protein With Future Cardiovascular Disease and All-Cause Mortality: The Cardiovascular Health Study. Circulation 2007; 116: 32,38.

45. Philip S. Mullinex, MD; Scott R. Steele, MD; Matthew J. Martin, MD; Benjamin W. Starnes, MD; Charles A. Andersen, MD. C-reactive Protein Level and Traditional Vascular Risk Factors in the Prediction of Carotid Stenosis. Arch Surg 2007; 142(11): 1066-1071.

46. Martin Schillinger, MD; Markus Exner, MD; Wolfgang Mlekusch, MD, et al. Inflammation and Carotid ArteryRisk for Atherosclerosis Study (ICARAS). Circulation 2005; 111: 2203-2209.

47. Beneficial effect of carotid endarterectomy in symptomatic patients with high-grade carotid stenosis. North American Symptomatic Carotid Endarterectomy Trial Collaborators. N Engl J Med 1991; 325(7): 445-53.

48. Yamagami H, Kitagawa K, Nagai Y, et al. Higher levels of interleukin-6 are associated with lower echogenicity of carotid artery plaques. Stroke 2004; 35: 677-681. 
49. Alvarez Garcia B, Ruiz C, Chacon P, Sabin JA, Matas M. High-sensitivity C-reactive protein in high-grade carotid stenosis: risk marker for unstable carotid plaque. $J$ Vasc Surg 2003; 38(5): 1018-24.

50. Lombardo A, Biasucci LM, Lanza GA, et al. Inflammation as a possible link between coronary and carotid plaque instability. Circulation 2004; 109(25): 3158-63.

51. Jander S, Sitzer M, Schumann R, et al. Inflammation in high-grade carotid stenosis: a possible role for macrophages and T cells in plaque destabilization. Stroke 1998; 29(8): 1625-30.

52. Grønholdt ML, Nordestgaard BG, Bentzon J, et al. Macrophages are associated with lipid-rich carotid artery plaques, echolucency on B-mode imaging, and elevated plasma lipid levels. J Vasc Surg 2002; 35(1): 137-45.

53. Handberg A, Skjelland M, Michelsen AE, et al. Soluble CD36 in plasma is increased in patients with symptomatic atherosclerotic carotid plaques and is related to plaque instability. Stroke 2008; 39(11): 3092-5.

54. Kunte H, Amberger N, Busch MA, Rückert RI, Meiners S, Harms L. Markers of instability in high-risk carotid plaques are reduced by statins. J Vasc Surg 2008; 47(3): 513-22.

55. McDermott MM, Guralnik JM, Corsi A, et al. Patterns of inflammation associated with peripheral arterial disease: the InCHIANTI study. Am Heart J 2005; 150(2): 276-81.

56. Brevetti G, Martone VD, de Cristofaro T, et al. High levels of adhesion molecules are associated with impaired endothelium-dependent vasodilation in patients with peripheral arterial disease. Thromb Haemost 2001; 85(1): 63-6.

57. Silvestro A, Scopacasa F, Ruocco A, et al. Inflammatory status and endothelial function in asymptomatic and symptomatic peripheral arterial disease. Vasc Med 2003; 8(4): 225-32.

58. Brevetti G, Piscione F, Silvestro A, et al. Increased inflammatory status and higher prevalence of three-vessel coronary artery disease in patients with concomitant coronary and peripheral atherosclerosis. Thromb Haemost 2003; 89(6): 1058-63.

59. Erren M, Reinecke H, Junker R, et al. Systemic inflammatory parameters in patients with atherosclerosis of the coronary and peripheral arteries. Arterioscler Thromb Vasc Biol 1999; 19(10): 2355-63.

60. Rossi A, Franceschini L, Fusaro M, et al,. Carotid atherosclerotic plaque instability in patients with acute myocardial infarction. Int J Cardiol 2006; 111(2): 263-6.

61. Tzoulaki I, Murray GD, Lee AJ, Rumley A, Lowe GD, Fowkes FG. C-reactive protein, interleukin-6, and soluble adhesion molecules as predictors of progressive peripheral atherosclerosis in the general population: Edinburgh Artery Study. Circulation 2005; 112(7): 976-83.

62. Brevetti G, Schiano V, Laurenzano E, et al. Myeloperoxidase, but not C-reactive protein, predicts cardiovascular risk in peripheral arterial disease. Eur Heart $J$ 2008; 29(2): 150-2.

63. Pasterkamp G, Schoneveld AH, van der Wal AC, et al. Inflammation of the atherosclerotic cap and shoulder of the plaque is a common and locally observed feature in unruptured plaques of femoral and coronary arteries. Arterioscler Thromb Vasc Biol 1999; 19(1): 54-8.

64. Vink A, Schoneveld AH, Richard W, et al. Plaque burden, arterial remodeling and plaque vulnerability: determined by systemic factors? J Am Coll Cardiol 2001; 38(3): 718-23.

65. Brevetti G, Piscione F, Cirillo P, et al. In concomitant coronary and peripheral arterial disease, inflammation of the affected limbs predicts coronary artery endothelial dysfunction. Atherosclerosis 2008; 201(2): 440-6.

66. Sirico G, Brevetti G, Lanero S, Laurenzano E, Luciano R, Chiariello M. Echolucent femoral plaques entail higher risk of echolucent carotid plaques and a more severe inflammatory profile in peripheral arterial disease. $J$ Vasc Surg 2008. [Epub ahead of print].

67. Rothwell PM, Villagra R, Gibson R, Donders RC, Warlow CP. Evidence of a chronic systemic cause of instability of atherosclerotic plaques. Lancet 2000; 355(9197): 19-24.

68. Bekos C, Pieri L, Angelides N, Moros I. Prevalence of multifocal atherosclerosis and comorbidity on symptomatic Cypriot inpatients. Int Angiol 2008; 27(5): 419-25.

69. Donnan GA, Fisher M, Macleod M, Davis SM. Stroke. Lancet 2008; 371(9624): 1612-1623.

70. Salameh MJ, Rundek T, Boden-Albala B, et al. Self-reported peripheral arterial disease predicts future vascular events in a community-based cohort. J Gen Intern Med 2008; 23(9): 1423-8.

71. Tsai AW, Folsom AR, Rosamond WD, Jones DW. Ankle-brachial index and 7-year ischemic stroke incidence: the ARIC study. Stroke 2001; 32(8): 1721-4.

72. Ovbiagele B. Association of ankle-brachial index level with stroke. J Neurol Sci 2008. [Epub ahead of print].

73. Abbott RD, Rodriguez BL, Petrovitch H, et al. Anklebrachial blood pressure in elderly men and the risk of stroke: the Honolulu Heart Program. J Clin Epidemiol 2001; 54(10): 973-8.

74. Chamorro A. Role of inflammation in stroke and atherothrombosis. Cerebrovasc Dis 2004; 17 (Suppl 3): $1-5$.

75. Musicant SE, Taylor LM Jr, Peters D, et al. J Prospective evaluation of the relationship between C-reactive protein, D-dimer and progression of peripheral arterial disease. Vasc Surg 2006; 43(4): 772-80.

76. Hogh AL, Joensen J, Lindholt JS, Jacobsen MR, Ostergaard L. C-reactive protein predicts future arterial and cardiovascular events in patients with symptomatic peripheral arterial disease. Vasc Endovascular Surg 2008; 42(4): 341-7.

77. Ridker PM, Hennekens CH, Stampfer MJ \& Wang F. (1998) Prospective study of herpes simplex virus, cytomegalovirus, and the risk of future myocardial infarction and stroke. Circulation; 98: 2796-2799.

78. Rost NS, Wolf PA, Kase CS, et al. (2001) Plasma concentration of C-reactive protein and risk of ischemic stroke and transient ischemic attack: the Framingham study. Stroke 32: 2575-2579.

79. Gussekloo J, Schaap MCL, Frölich M, Blauw GJ \& Westendorp RGJ. (2000) C-reactive protein is a strong but non-specific risk factor of fatal stroke in elderly persons. Arterioscler Thromb Vasc Biol 20: 1047-1051.

80. Zaremba J, Losy J. The levels of TNF-alpha in cerebrospinal fluid and serum do not correlate with the counts of the white blood cells in acute phase of ischaemic stroke. Folia Morphol (Warsz) 2001; 60: 91-7.

81. Pedersen ED, Waje-Andreassen U, Vedeler CA, Aamodt G, Mollnes TE. Systemic complement activation following human acute ischaemic stroke. Clin Exp Immunol 2004; 137: 117-22.

82. Vila N, Filella X, Deulofeu R, Ascaso C, Abellana R, Chamorro A. Cytokine-induced inflammation and longterm stroke functional outcome. J Neurol Sci 1999; 162: $185-8$.

83. Emsley HC, Smith CJ, Gavin CM, et al. An early and sustained peripheral inflammatory response in acute ischaemic stroke: relationships with infection and atherosclerosis. J Neuroimmunol 2003; 139: 93-101.

84. Chuaqui R, Tapia J. Histologic assessment of the age of recent brain infarcts in man. J Neuropathol Exp Neurol 1993; 52: 481-9.

85. Mena H, Cadavid D, Rushing E. Human cerebral infarct: a proposed histopathologic classification based on 137 cases. Acta Neuropathol (Berl). 